\title{
Geografía y lingüística
}

\author{
Francisco Abad Nebot *
}

\begin{abstract}
RESUMEN
Este ensayo analiza y sitúa en un contexto adecuado de doctrinas dos textos muy relevantes acerca de la geografía y lo lingüistico, que sin embargo no parecen haber llamado la suficiente atención: unas páginas de

Saussure y otras de E. Coseriu. Además se hace referencia al inicio del estructuralismo y de la sociología en los análisis dialectales.

ABSTRACT

This essay analyses and places two very relevant texts about Geography and Linguistics, in the right doctrinal context. However, these pages of Saussure and E. Coseriu do not appear to have been sufficiently appealing. Furthermore, reference is made to the beginning of structuralism and sociology in dialectal analyses.
\end{abstract}

\section{Introducción}

La trayectoria doctrinal y en la práctica de la geografía lingüística sabido es que la trazó lorgu lordan en su texto luego citado, Lingüistica Románica. Evolución, corrientes, métodos; por supuesto existen otras reseñas anteriores, pero la presente tiene la ventaja de que en ella se considera hasta los años sesenta del siglo xx.

No obstante en el mundo español e hispánico -o sea, el mundo de nuestra lengua-, han de tenerse presentes otras contribuciones que hay que registrar sucesivamente en cuanto tales, obra de Eugenio Coseriu, de

* Facultad de Filología. UNED. 
Diego Catalán, de Manuel Alvar, etc. Son páginas acaso más conocidas en ocasiones por sus títulos que vistas y manejadas de verdad, pues pocas veces se las emplea más allá de la mención de su ficha bibliográfica; como decimos, una historiografía seria de lo que se refiere a la geografía lingüística y la dialectología han de registrarlas y tenerlas presentes, y es lo que haremos ahora de manera sucinta en los párrafos que van a seguir del presente ensayo.

Antes no obstante nos proponemos volver a llamar la atención -alguna vez lo hemos hecho ya- acerca de unas páginas del Curso de Lingüística General de Ferdinand de Saussure que esta vez sí que cabe decir que parecen haber pasado completamente inadvertidas: nos referimos a su "Cuarta Parte: Lingüística geográfica", que al menos nosotros nunca hemos visto glosadas ni incluso por varios especialistas ${ }^{1}$.

\section{Lenguas literarias y dialectos}

Proclamaba en los pasajes aludidos Saussure que entre dialecto y lengua «hay una diferencia de cantidad, no de naturaleza», y así ocurre en efecto $^{2}$; se trata en ambos casos de códigos idiomáticos y por tanto de realidades de una misma naturaleza, mientras que las diferencias que los caracterizan respectivamente son cualitativas: el dialecto supone algunas divergencias respecto de la lengua de la que procede, posee innovaciones en el hablar a partir del punto de partida desde el que se ha formado. El dialecto se diferencia parcialmente de la lengua, tiene rasgos privativos que lo alejan cuantitativamente del idioma del que ha partido.

De su parte Menéndez Pidal caracterizaba al castellano como lengua y no ya como lo que fue un dialecto, por servir de instrumento a una literatura de importancia y "por haber absorbido en sí a los romances leonés y navarro-aragonés ${ }^{3}$ : las lenguas - a diferencia de los dialectos- poseen una tradición literaria constante, caudalosa y prestigiosa, y se sobreponen a otros dialectos del mismo origen. Las lenguas se diferencian cuantitativamente de la lengua de la que a su vez proceden, y por su parte y en sentido descendente, se diferencian cuantitativamente de los dialectos que

\footnotetext{
Por ejemplo no sabemos que lo haya hecho ninguno de los autores del ALEA, o de los otros Atlas de España por regiones.

Saussure, F. DE, Curso..., trad. de Amado Alonso, Buenos Aires, Losada, 1981²1, pág. 308

MENÉNDEZ PIDAL, Ramón, Manual de gramática histórica española, que citamos por la vigésima ed., Madrid, Espasa-Calpe, 1981, §1.
} 
en ellas se originan. Por lo demás y en la estimación pidalina, la lengua española no dejó de constituir un complejo dialectal interior: podemos referir la absorción que hizo el castellano del leonés hacia la época de Fernando III el Santo, y la del aragonés con la época de Fernando el Católico de Aragón ${ }^{4}$.

Manifestaba asimismo Saussure que el principio más general que impulsa la diversidad lingüística es el de "la separación geográfica» 5 : Ia incomunicación espacial de las comunidades hablantes las lleva a la fractura idiomática, y por ello a los procesos de dialectalización y en definitiva --en ocasiones - de ininteligibilidad lingüística; estamos ciertamente ante el mayor factor de diferenciación en los códigos idiomáticos.

Describía por igual Saussure cómo en la historia ciertamente uno de los dialectos se hace lengua, y absorbe idiomáticamente a otros dialectos; el párrafo es precioso, e ilustra muy bien lo que el propio Menéndez Pidal trazó que había ocurrido en la Península:

Entendemos por «lengua literaria» no solamente la lengua de la literatura, sino [...] toda especie de lengua culta, oficial o no, al servicio de la comunidad entera. Abandonada a sí misma, la lengua sólo conoce dialectos, ninguno de los cuales se impone a los demás, y con ello está destinada a un fraccionamiento indefinido. Pero como la civilización, al desarrollarse, multiplica las comunicaciones, se elige, por una especie de convención tácita, uno de los dialectos existentes para hacerlo vehículo de todo cuanto interesa a la nación en su conjunto. [...] Una vez promovido al rango de lengua oficial y común, el dialecto privilegiado rara vez sigue siendo como era hasta entonces. Se le mezclan elementos dialectales de otras regiones; se hace cada vez más complejo ${ }^{6}$.

Las lenguas se exponen pues a un fraccionamiento indefinido por causa principal de la separación geográfica, de la incomunicación entre

\footnotetext{
4 En un párrafo expresivo, escribió una vez don Ramón: «El idioma sufre ahora en sus rumbos el giro más amplio y fuerte que en mil años de vida ha experimentado. El advenimiento de los Reyes Católicos unifica definitivamente los dos grandes dialectos afines, castellano y aragonés, que seguian separados; hecho de tal importancia que necesitamos ascender al siglo xIII para hallar otro semejante en la unificación del castellano y el leonés bajo Alfonso el Sabio. [...] Los correctores de pruebas tipográficas [del reinado de Fernando e Isabel] fueron el organismo, aunque poco organizado, que más hizo por uniformar la lengua literaria. [... Jorge Manrique] quiebra la dirección estilistica predominante en la alta líteratura. $Y$ después los descubrimientos geográficos, la dispersión de los judios españoles, las empresas de Italia, son sucesos llamados a modificar como ningún otro la vida del idioma, que antes transcurría muy casera». Vid. MENÉNDEZ PIDAL, R., "La lengua en tiempo de los Reyes Católicos", Cuadernos Hispanoamericanos, 13, 1950, págs. 9-24: págs. 9-10.

5 Op. cit., pág. 309.

6 Ibid., pág. 312
} 
los grupos humanos; a una lengua literaria común se llega por convención tácita, dice nuestro autor, o explicado con otras palabras, por la fuerza de la realidad y de los hechos, que pueden ser la mayor fortuna política, las razones de prestigio, el mayor desarrollo literario, etc. En el caso peninsular, constituye un dato cierto -y Menéndez Pidal lo subrayó con fórmulas de las que vamos a hacernos eco-, el de que en los primeros siglos modernos el castellano o español se hizo lengua común entre otras cosas porque "comprendió en sí los productos literarios de toda España" '. La abundancia de la producción literaria y "la frecuente superioridad de sus autores" ${ }^{8}$ hicieron del castellano la lengua española, según la explicación filológica pidalina.

Pero hay que saber que a un dialecto llevado por la fuerza de los hechos políticos o culturales al rango de lengua literaria común, se le mezclan elementos dialectales de otras regiones: este carácter de "mezcla" define muy bien todas las situaciones idiomáticas, y en el caso español ocurrió en efecto que la lengua común se constituyó en tanto un "complejo dialectal» (Vicente García de Diego).

En efecto fue - y según es sabido- el dialectólogo García de Diego quien ya tempranamente postuló que «acaso algunos de los [dialectalismos] admitidos comúnmente por tales, como nalga, no deben excluirse del castellano por el solo hecho de discordar de leyes fonéticas quizá prematuramente formuladas" ' ; es decir, se trata de que hay las que nuestro autor denomina "variantes subdialectales internas". Sin embargo y por lo que a este ejemplo específico respecta, Menéndez Pidal insistió en que estamos ante una forma leonesa ${ }^{10}$, lo que de todas maneras ilustra por igual el que el castellano consiste en ser un complejo dialectal, bien se entienda que por la existencia de subdialectos internos en el mismo o por la presencia en él de casos de origen dialectal leonés, etc.

Fue sin embargo más de treinta años más tarde cuando García de Diego proclamó, en palabras absolutamente de referencia en las doctrinas lingüisticas de la filologia española:

En todo estudio del castellano habrá que tener muy en cuenta su condición de complejo dialectal.

Menéndez Pidal, R., España y su historia, Madrid, Minotauro, 1957, II, pág. 673.

Menéndez Pidal, R., En torno a la lengua vasca, Buenos Aires, Espasa-Calpe, 1962, pág. 55 .

García de Diego, V., "Dialectalismos», Revista de Filologia Española, III, 1916, págs. 301. 318.

10 Manual..., $\S 60.3$. 
El castellano sólo tiene conciencia defensiva frente a los grandes dialectos conservados, como el gallego o el catalán. Sobre los dialectos inconsistentes barridos por él y en parte solapadamente subsistentes, el castellano obra sin cautela, aceptando lo que encuentra. Esta es la paradoja de que el español es dialectalmente pobre frente al francés y el italiano y es más rico en dialectalismos.

[...] El castellano ha mezclado, ya sin separación posible, sus elementos y los regionales, dejando de considerarlos extraños ${ }^{11}$.

En realidad a lo que se está refiriendo nuestro autor es a la lengua común literaria o lengua española, y al hacerlo y comprobar los dialectalismos subsistentes en ella proclama la fórmula de que el español resulta dialectalmente pobre (en comparación con las otras lenguas románicas), y sin embargo es rico en dialectalismos. Creemos que al mantener a su vez cómo en español no hay escritores dialectales sino escritores con dialectalismos, Manuel Alvar conservaba mentalmente la formulación de García de Diego, y la aplicaba al caso de la llamada poesía española dialectal ${ }^{12}$.

Cualquier situación idiomática es realmente dialectal y diferenciada interiormente, y por eso García de Diego afirma además que «aun los dialectos evolucionados en un lugar son un complejo dialectal», y lo ejemplifica con el caso del asturiano, el cual posee muchos subdialectos ${ }^{13}$.

\section{Caracteres dialectales vs. dialectos}

Venimos viendo cómo algunos hechos fundamentales en la relación entre la geografía y la cultura de una parte, y la lengua, los estableció ya Ferdinand de Saussure, y en este sentido debemos hacernos cargo de otra observación suya: la de que las innovaciones que dan lugar a la evolución idiomática de ordinario no alcanzan "más que a una porción del dominio, teniendo cada hecho dialectal su área especial» ${ }^{14}$. Nos encontramos con un dato de gran relevancia, que consiste en la gran diversificación interior de cualquier dominio idiomático, ya que las isoglosas que traducen cada hecho lingüístico no coinciden entre sí en su distribución espacial, sino que se superponen y entrecruzan ${ }^{15}$; esto es

\footnotetext{
"García de Diego, V., "El castellano como complejo dialectal y sus dialectos internos", RFE, XXXIV, 1950, págs. 107-124: pág. 107.

12 Alvar, M. Estudios y ensayos de literatura contemporánea, Madrid, Gredos, 1971, pág. 318.

13 Loc. cit., pág. 124.

14 Curso..., pág. 318.

15 Por isoglosas han de entenderse las «líneas imaginarias que en un mapa representan los límites de un mismo fenómeno lingüistico con los puntos intermedios entre ambos", de acuerdo con la definición académica.
} 
fundamental, saber que espacialmente los límites idiomáticos son muchas veces entrecruzados más que lineales, y ya los estudios del mismo don Ramón Menéndez Pidal dejaron en claro la manera de producirse tales limites según la región peninsular fuese de reconquista más tardia o no.

En definitiva Saussure llegó a una especie de formulación que nos parece decisiva, aunque no recordamos haberla visto recogida nunca: se trata pues de que no hay más que caracteres dialectales, no hay dialectos ${ }^{16}$. Entiéndanse estas palabras: existen por supuesto los dialectos y podemos hablar de ellos, pero consisten en un conjunto de caracteres dialectales entrecruzados, que abarcan una u otra parte del territorio y no lo comprenden uniformemente.

Los códigos idiomáticos cumplen en el territorio una evolución y diversificación lingüísticas diferenciadas, se diferencian interiormente según rasgos fonéticos, morfológicos, sintácticos o léxico-semánticos, pero a pesar de tal complejidad interna sigue siendo posible hablar de lenguas generales y de dialectos. Los caracteres dialectales pueden llegar a coincidir según otras tantas concordancias espaciales, y "cuando esas concordancias - manifestaba Saussure - son suficientemente numerosas[,] se puede hablar de dialecto por aproximación. Tales concordancias se explican por hechos sociales, políticos, religiosos, etc.» ${ }^{17}$.

Esta idea de la existencia de haces de isoglosas o entrecruzamiento de caracteres dialectales la asumió la romanística, y una muestra de ello es un pasaje de Menéndez Pidal pocas veces recordado y que cabe tener presente; en cualquier caso hay que decir que don Ramón no seguía en sus doctrinas necesariamente a Saussure y nada más que a Saussure, sino que en general tuvo a la vista a los más importantes teóricos de la lingüística románica y elaboró a partir de sus lecturas una doctrina expuesta de modo personal.

Al respecto que nos importa ahora decia efectivamente Menéndez Pidal:

Un dialecto no tiene un único límite fijo [...]; los muy varios caracteres que distinguen esos dialectos de los vecinos, no tienen todos en masa una misma extensión, sino que cada uno de ellos alcanza por lo común un límite distinto del de los demás, siguiendo cada uno direcciones muy diversas. [... Los límites de cada innovación] dependen de las circunstancias especiales

16 Op. cit., pág. 320.

17 Ibid., pág. 324. 
de expansión y de influencia que cada grupo innovador posee y desarrolla en cada momento especial de su historia ${ }^{18}$.

Los grupos humanos - siempre a partir de un primer individuo hablante- dan lugar a posibles innovaciones en los rasgos o caracteres idiomáticos, y tales innovaciones se difunden de acuerdo con las circunstancias particulares históricas del grupo: ocurre de esta manera que unas innovaciones bien por su lugar de origen, bien por los caracteres de la situación en la que ocurren, etc., alcanzan una vigencia y otras otra, de tal modo que el resultado idiomático es el del entrecruzamiento y mezcla de las isoglosas. Debe tenerse no obstante un bien entendido: que la diversificación interna de cualquier hablar ha de ser lo suficientemente relativo, como para que permita la inteligibilidad y la intercomprensión entre los hablantes; de ahí las concordancias suficientemente numerosas que siempre se dan en el seno de una lengua o de un dialecto, y a las que hemos visto referirse a Saussure.

Además el maestro ginebrino señalaba cómo los lindes de lenguas y dialectos se encuentran ahogados en las transiciones, aunque hay circunstancias que impiden que subsistan esas transiciones ${ }^{19}$ : quiere esto decir que los haces de isoglosas en que consiste cada código idiomático dan lugar en principio a zonas de transición lingüística, no a fronteras lineales entre lenguas o entre dialectos. Lo idiomático se constituye así espacialmente en una especie de continuum más o menos gradual.

El hablar forma un continuum espacial, decimos, pero ocurre en ocasiones que si se considera un punto dado del territorio, "todo carácter que nc pertenezca más que al hablar del punto en cuestión[,] se debe a la fuerza de campanario" ${ }^{20}$; esta fuerza de campanario o espíritu particularista es una manifestación de la incidencia en la lengua de los hechos generales de distribución geográfica, y es justamente contraria a las fuerzas unificadoras que derivan de todo intercambio. Hay por tanto un "espíritu de campanario" y una "fuerza unificadora»: lógicamente "cuanto más favorezca el intercambio una innovación, más se extenderá su área; en cuanto al espíritu de campanario, su acción consiste en mantener un hecho lingüístico en los límites que haya adquirido, defendiéndolo contra las competencias de fuera» ${ }^{21}$.

\footnotetext{
18 En torno..., pág. 45-46.

19 Curso de lingüistica general, pág. 325.

20 Ibid., pág. 330.

21 Ibid., pág. 331.
} 
Ya decimos que la presente cuarta parte del Curso... saussureano no debiera haber pasado bastante inadvertida, pues apenas si se la recuerda; está evocada no obstante - y no podía ocurrir de otra manera- en el panorama de lordan, en el que por ej. se interpreta así al maestro de Ginebra: "Gracias a la vecindad geográfica, las particularidades de un habla se pueden difundir, y de este modo aparecen las llamadas líneas de isoglosas o limites de los caracteres dialectales [...]. Las innovaciones lingüisticas se propagan bajo el imperio de dos fuerzas: una centrípeta [...] y otra centrífuga [...], que luchan entre sí”; estas fuerzas son respectivamente la del conservadurismo local, y la de las relaciones y las comunicaciones ${ }^{22}$. El mismo lordan no parece avalorar mucho las observaciones saussureanas que acabamos de ver, ni tampoco lo hace el anotador español de su libro Manuel Alvar; nosotros creemos en cambio que se trata de una aportación muy sugeridora.

\section{Un escrito de Eugenio Coseriu}

A "geografía y lingüistica» está dedicado el primer capitulillo del escrito de Eugenio Coseriu en torno a La geografía lingüística: encontramos en estas páginas una aportación temprana y de gran claridad conceptual a la materia, en el contexto de los estudios de lengua española; de hecho son páginas completamente vigentes, salvo en la información sobre las tareas cumplidas con posterioridad a la fecha en que fueron escritas (1954).

La primera definición que hace Coseriu es por lógica la de qué sea la geografía lingüística, y dice en sus palabras así: "La expresión "geografía lingüística» designa exclusivamente un método dialectológico [...] que presupone el registro en mapas especiales de un número relativamente elevado de formas lingüísticas (fónicas, léxicas o gramaticales) comprobadas mediante encuesta directa y unitaria en una red de puntos de un territorio determinado" ${ }^{23}$. Tenemos por tanto un territorio escogido, $y$ en el mismo se selecciona una red de puntos y mediante encuesta dialectal directa en tales puntos, se obtienen formas idiomáticas que luego se cartografian; en este sentido ha podido estimarse que lo que representa un mapa lingüístico es un cuadro sinóptico de hechos idiomáticos según su

22 IORdan, I., Lingüística Románica. Evolución, corrientes, métodos, Madrid, Eds. Alcalá, 1967, pág. 519. Corregimos un lapsus del texto, en el que lo centrípeto se define como centrífugo y viceversa.

23 Citamos por Coseriu, E., "La geografia lingüistica», en El hombre y su lenguaje, Madrid, Gredos, 1977, pàgs. 103-158: pág. 103. 
distribución geográfica ${ }^{24}$. Realmente del contraste y superposición de mapas - por ej.,- - han podido obtenerse a veces resultados inéditos y brillantes ${ }^{25}$.

Con simultaneidad al escrito de Coseriu, Karl Jaberg definió a su vez qué son los Atlas lingüísticos. Delimitaba entonces (1954-55) los Atlas de grandes y de pequeños dominios, y definía con estas palabras los primeros: "Un atlas grande (atlas nacional) es la proyección cartográfica de las peculiaridades dialectales de un país. Se basa en el inventario llevado a cabo en una serie de puntos de encuesta previamente seleccionados, que se limitan a verificar la realización local de un determinado número de hechos lingüísticos» 26 .

Tales Atlas de grandes dominios ponen de relieve - caracterizaba además Jaberg- el influjo de las capitales de provincia en cuanto centros lingüisticos, y de esta manera cabe ver los procesos de difusión de las innovaciones en las maneras de hablar ${ }^{27}$.

Por otro lado existen los Atlas de pequeños dominios, y en esta mitad de los años cincuenta del siglo xx los caracterizaba a su vez Jaberg al indicar que un atlas regional consiste en cla representación cartográfica de un dominio dialectal más o menos cerrado que se diferencia de los dialectos vecinos por la combinación de propiedades lingüísticas típicas" ${ }^{28}$. En este caso nos encontramos con que el Atlas pequeño lleva a poder determinar «el intercambio lingüístico de localidades vecinas» 29.

\section{Realidades geográficas y hechos idiomáticos}

Del interés que para las disciplinas propiamente geográficas presenta esta geografía lingüística a la que nos referimos se ocupa también Coseriu -es el único lingüista al que hemos visto hacerlo-, y escribe de esta manera, en esencia:

24 IORDAN, Lingüistica..., pág. 254.

$25 \mathrm{C}$ r. distintas páginas de Catalan, D., El español. Origenes de su diversidad, Madrid, Paraninfo, 1989 .

26 Citamos por la agrupación de articulos que se hace en JABERG, K., Estudios de geolingüistica, Universidad de Granada, 1995, pág. 15.

${ }_{27}^{27}$ «El atlas grande — decía el autor- puede seguir la transmisión de las innovaciones desde los grandes centros a los pequeños en todos sus grados intermedios, y además, el directo saltar de la chispa hasta la última aldea de montaña» (lbid., pág. 16).

28 Ibid., pág. 17.

29 Ibid. 
Las comprobaciones de la geografía lingüística [...] se relacionan estrechamente con la geografía como tal y no pueden dejar de interesar a esta disciplina - en la medida en que considera la tierra como «habitat" del hombre [...-, ] porque revelan un aspecto esencial de las relaciones entre la vida social y cultural del hombre y su ambiente natural ${ }^{30}$.

En efecto la geografía considera las condiciones ambientales en que se desarrolla la vida de los hombres, y la geografía lingüística puede servir de indicio y testimonio de algunas de tales condiciones. Si el hábitat constituye una variable independiente -podemos decir-, 10 idiomático será la variable dependiente de la relación, y como variable dependiente testimonia la concreta consistencia de la variable independiente; además lo idiomático (condicionado o no) presenta interés por sí mismo, y suele ser de lo que se ocupa el filólogo.

Un caso específico es el aludido por Albert Dauzat: en Francia -ilustra este autor - «sólo las comunidades de habitantes — municipios [...] - son en principio las verdaderas células lingüísticas, cuya yuxtaposición forma el mosaico vivo de nuestras hablas regionales" ${ }^{31}$.

Concreta asimismo Coseriu cómo los “centros de irradiación» idiomática de los que habla la geografía lingüística son los centros políticos, administrativos, comerciales, etc., que asimismo se consideran "centros "propiamente geográficos"»; del mismo modo

los obstáculos «naturales» -ríos, montañas, mares- no son siempre y necesariamente tales desde el punto de vista de la geografía lingüística, asi como no lo son desde el punto de vista de la geografía política: al contrario, ciertos grandes ríos (como el Rhin, el Danubio, el Río de la Plata) son a menudo puentes de comunicación [...] Tampoco las zonas lingüísticamente "aisladas" coinciden siempre y necesariamente con las zonas naturalmente aisladas (por ej., islas o valles de alta montaña, de difícil acceso), si no son "aisladas" también política o económicamente ${ }^{32}$.

Ocurre pues que los centros de irradiación idiomática son los llamados centros propiamente geográficos: razones de relevancia y prestigio admi-

30 Loc. cit., págs. 104-105.

31 Y prosigue poco más adelante: «No es la aldea, en principio, la unidad lingüística, sino el municipio, que puede comprender varias aldeas. Estas agrupaciones han vivido hasta el siglo $x i x$, muy aisladas unas de otras, a pesar de su proximidad territorial. Ante todo a causa de la dificultad de los medios de comunicación. Sin hablar de los ferrocarriles, no olvidemos que los caminos, exceptuando algunas grandes arterias, no datan más que de comienzos del siglo xix. Los caminos de explotación no salían del municipio; los caminos de comunicación eran escasos y malos". Vid. Dauzat, A., La vida del lenguaje, trad. cast., Buenos Aires, El Ateneo, 1946, págs. 181-182.

32 Loc. cit., págs. 106-107. 
nistrativo o comercial, etc., hacen de ellos que se constituyan en referencia de los modos de hablar. Cuando operan estas razones de prestigio, o simplemente y más en general cuando hay o ha habido comunicación, idiomáticamente se produce una expansión y vigencia de las formas lingüísticas; en definitiva ocurre que ha de contarse con la geografía política de las sucesivas épocas: se trata -indica el propio Coseriu - "de condiciones geográfico-históricas que facilitan o dificultan la interpenetración lingüística" ${ }^{33}$.

Las condiciones ambientales y culturales o de civilización, dejan su impronta en la distribución geográfica de los fenómenos idiomáticos; de ahí la necesidad que tiene el dialectólogo de conocer las condiciones geográficas de los lugares que estudie: comarcas, centros urbanos...

En fin apunta el lingüista rumano algo que nunca ha estado inadvertido, y es que la geografía lingüística puede entenderse sin más como parte de la geografía en cuanto consiste en una "geografía de las lenguas" actuales o del pasado: "el estudio de la distribución de las "lenguas" (comunidades lingüísticas) sobre la tierra y de las fronteras entre ellas cabe dentro de la geografía política» ${ }^{34}$. De esta manera -y por poner un ejemplo muy a mano- en el conocido Compendio de Gourou y Papy, se dedica un pequeño epígrafe a la "diversidad de las lenguas» y al asunto de de las «lenguas progresivas y lenguas en retroceso" ${ }^{35}$; los presentes autores comprueban que en efecto «hay lenguas que teniendo a su favor un gran prestigio, la autoridad política o la influencia económica, se han superpuesto a otras lenguas y han conquistado un inmenso auditorio".

La historia ilustra en el caso del español que la autoridad política castellana más el prestigio de su literatura, hicieron del dialecto castellano la llamada lengua española.

Desde luego el presente escrito de Coseriu incluye muchas otras consideraciones, pero ahora sólo queríamos subrayar y glosar aquellas más generales referidas a "geografía y lingüística"; el autor hace al final de sus páginas unas conclusiones que al menos muy en abreviatura debemos transcribir, y escribe por ej.:

La geografia lingüística ha contribuido a demostrar con toda evidencia que cada cambio lingüistico parte, en último análisis, de un individuo hablante y se difunde por razones sociales y culturales; [...] que los cambios fo-

\footnotetext{
Ibid., la misma pág. 107

lbid., págs. 109-110.

Gourou, P. y PAPY, L., Compendio de geografia general, Madrid, Rialp, 1980 ${ }^{15}, \S 17$, III.
} 
néticos se difunden con las palabras y que cada fenómeno tiene su área de difusión [...]; que los fenómenos lingüísticos, no sólo los léxicos sino también los fónicos y gramaticales, pasan de una "lengua" a otra; que las palabras son formas de cultura que acompañan en su difusión los conceptos y los objetos de civilización ${ }^{36}$.

El cambio idiomático en efecto no ocurre simultáneamente en todo el dominio hablante y no es fatal e ineluctable, según postulaba el positivismo; tiene en cambio un origen particular y que podemos circunscribir, y desde tal origen se difunde merced a que existen canales de comunicación, estimaciones favorables, etc. Desde luego creemos también que el cambio fonético se propaga mediante las palabras en que ese cambio se ha cumplido y aparece, induciendo a un interlocutor a cumplirlo asimismo, y resulta evidente que la historia de las palabras se halla implicada en un grado u otro con la historia de las cosas ${ }^{37}$. Hechos de geografía más hechos de civilización y de formas de vida, etc., condicionan y explican los hechos idiomáticos, y esto no es sólo la postura doctrinal de una o varias escuelas lingüísticas, sino que por constituir un hecho empírico debería ser asumido por cualquier enfoque que se haga de las lenguas.

Al terminar las presentes consideraciones cabe añadir además la lúcida inteligencia analítica con la que operó siempre Coseriu: de ahí la fuerza de sus teorizaciones y la vigencia de las mismas, más allá de lo que han supuesto en vida suya. No conocemos a otro autor que directamente en lengua castellana haya escrito observaciones tan clarividentes por lo que se refiere - en este caso- a la geografía lingüística.

\section{De la geografía lingüistica a la sociolingüística}

Más en nuestros días dos ponencias de sendas reuniones técnicas celebradas en Bucarest, fueron encargadas a Manuel Alvar: en ambos casos se trató de informar acerca de los Atlas lingüísticos y de la dialectología románicos, tal como se mostraban respectivamente en 1959 y 1968; estos informes dieron lugar a su vez al volumen suyo conjunto Estructuralismo, geografía lingüistica y dialectología actual (1969, y edición ampliada en 1973).

\footnotetext{
36 "La geografia...", pág. 154

37 Vid. los motivos que ilustra JABERG, K., en su Geografia lingüistica, trad. cast., Universidad de Granada, 1959, y sobre todo en Aspects géographiques du langage, Paris, Droz, MCMXXXVI, quien proclama la relevancia de lo que denomina "la biología del lenguaje", la sociología lingüistica, y las relaciones entre palabras y cosas (págs. 19 y \$s.).
} 
El trabajo sobre "Los nuevos atlas lingüísticos de la Romania" se inicia recogiendo el autor el deslinde que ya hemos visto en Karl Jaberg entre los atlas de grandes y de pequeños dominios ${ }^{38}$, para ocuparse luego de los segundos: apuesta en ellos por la precisión fonética junto a la valoración fonológica; por el uso de cuestionario único; por la pluralidad de investigadores siempre que no se llegue a la atomización del trabajo; por asimismo una pluralidad de informadores en cada localidad; por el análisis de los hechos de sociología lingüistica; o por la atención a lo etnográfico ${ }^{39}$. Estamos pues ante la exposición de asuntos técnicos más que teóricos, resueltos de acuerdo con la experiencia del prof. Alvar al ir elaborando el Atlas lingüístico de Andalucía ( $A L E A)$.

El otro escrito sobre el «estado actual» de la dialectología románica ya queda dicho que data de 1968; era un momento de plenitud en la vigencia de las doctrinas estructurales, y se trató de un panorama de teorías - hecho según el entender del autor-, y de consideraciones más desarrolladas acerca de la sociología idiomática. Además de José Pedro Rona - a quien se menciona-, ha de saberse que otro estudioso que desde aquellos tiempos y en los inmediatamente posteriores se dedicaría a las presentes cuestiones al otro lado del Atlántico, fue Juan Miguel Lope Blanch.

Estos escritos de Rona, de Alvar, de Juan Miguel Lope, etc., hechos cada uno según su estilo personal, suponían - si cabe decirlo así- la comprobación de la vigencia de una especie de nuevo paradigma en los análisis de geografía, ordenación social, y lingüística. En tal paradigma se mueve desde entonces en buena medida la dialectología del español.

\section{REFERENCIAS BIBLIOGRÁFICAS}

AlvaR, M. (1971): Estudios y ensayos de literatura contemporánea, Madrid, Gredos.

- $\left(1973^{2}\right)$ : Estructuralismo, geografía lingüistica y dialectología actual, Madrid, Gredos.

CATALÁN, D. (1989): El español. Origenes de su diversidad, Madrid, Paraninfo.

COSERIU, E. (1977): “La geografía lingüistica», en El hombre y su lenguaje, Madrid, Gredos, págs. $103-158$.

Dauzat, A. (1946): La vida del lenguaje, trad. cast., Buenos Aires, El Ateneo.

Garcia de DIEGo, V. (1916): “Dialectalismos», Revista de Filología Española, III, págs. 301-318.

- (1950): "El castellano como complejo dialectal y sus dialectos internos", RFE, XXXIV, págs. 107-124.

Gourou, P. y PAPY, L. (1980'5): Compendio de geografía general, Madrid, Rialp.

Iordan, I. (1967): Lingüistica Románica. Evolución, corrientes, métodos, Madrid, Eds. Alcalá.

38 Alvar, M., Estructuralismo..., Madrid, Gredos, 1973², pág. 111.

39 Ibid., págs. 117 y ss. 
JABERG, K. (1959): Geografia lingüística, trad. cast., Universidad de Granada.

- Aspects géographiques du langage, Paris, Droz, MCMXXXV!.

- (1995): Estudios de geolingüística, Universidad de Granada.

MENÉNDEZ PIDAL, R. (1981): Manual de gramática histórica española, vigésima ed., Madrid, Espasa-Calpe.

- (1950): "La lengua en tiempo de los Reyes Católicos", Cuadernos Hispanoamericanos, 13, págs. 9-24.

- (1957): España y su historia, Madrid, Minotauro, 1957.

- (1962): En torno a la lengua vasca, Buenos Aires, Espasa-Calpe, 1962.

SAUSSURE, F. DE (198121): Curso de Lingüistica General, trad. de Amado Alonso, Buenos Aires, Losada. 